\title{
Propensity of the managers to outsource hospital services in Shiraz, Iran
}

\author{
Zahra Kavosi ${ }^{1}$, Fatemeh Setoodehzadeh ${ }^{2}$, Erfan Kharazmi ${ }^{3}$, Mohammad Khammarnia $^{4}$, Ramin Ravangard $^{5}$ \\ ${ }^{1,3,5}$ Assistant Professor, Department of Health Services Management, School of Management and Medical \\ Information, Shiraz University of Medical Sciences, Shiraz, Iran. ${ }^{2} \mathrm{PhD}$ Students, Department of Health Policy, \\ Tehran University of Medical Science, Tehran, Iran. ${ }^{4}$ Lecturer, Health Promotion Research Center, Zahedan \\ University of Medical Sciences, Zahedan, Iran.
}

\begin{abstract}
Contracting out of health services to the private sectors has been the subject of extensive debate and discussion among health personnel and policymakers. Outsourcing is now considered as a useful management tool for health care managers in the public sector. Outsourcing increases efficiency and service quality, reduces costs, focuses on core processes, improves skills, enhances the overall competitive advantages of the organization, and creates effective occupations in the private sector. The present study aimed to determine the present status of outsourcing hospital services (i.e. radiology, laboratory, nursing, and nutrition) to the private sectors and the propensity of the managers to outsourcing services in six hospitals affiliated to Shiraz University of Medical Sciences, Iran. The study was conducted in six hospitals of Shiraz, Iran in 2012. The study population included all hospitals managers and the sample size was 24 . The findings of the study revealed that nutrition, radiology and laboratory services were being outsourced by the hospitals to the private sectors. None of the hospitals outsourced the nursing services. Nutrition service was outsourced by five of the six hospitals, and radiology and laboratory services were outsourced by only one hospital. The highest propensity for outsourcing services among the studied hospital managers were nutrition $(87 \%)$ followed by laboratory $(73.9 \%)$, radiology $(62.2 \%)$ and nursing services $(43.3 \%)$. Hospital managers and health policy makers should pay more attention to the characteristics of services, besides considering the costs, while outsourcing the services. An effective national policy should be developed to engage the private sectors to improve public health by outsourcing health services.
\end{abstract}

Keywords: Outsourcing, Hospital services, Managers, Efficiency, Iran.

\section{Introduction}

Nowadays financial provision for the health system is a major concern for both developed and developing countries because healthcare provision includes $9 \%$ of the global products. ${ }^{1}$ For developing countries, financial provision remains a major concern to improve population's health because these countries include $84 \%$ of the world population as well as tolerate $93 \%$ of the burden of the diseases. ${ }^{2}$ Ironically, these countries only share $18 \%$ of the world income and spent $11 \%$ of the world health expenditures. ${ }^{2}$

Restoring the structure of financial resources is considered as one of the policies for revising the health system in developing countries. ${ }^{1}$ In doing so, privatization is suggested as a method for providing effective treatment and outsourcing the services is considered as one of the interventions to improve quality and reduce costs. ${ }^{1,2}$ In fact, outsourcing is a mechanism for purchasing a particular service and its amount where quality is defined and its price is agreed upon. ${ }^{3}$ Outsourcing leads to downsizing the hospital workforce, reduction of the expenses, increase in efficiency as well as quality of the services, creation of effective job opportunities in the private sector, transfer of technology, attracting investment from other sectors. ${ }^{4}$ In addition, it can improve the goals of the

\section{Practice Points}

- Contracting out of health services to the private sectors has been the subject of extensive debate and discussion among health personnel and policymakers.

- The findings of the study revealed that nutrition, radiology and laboratory services were being outsourced by the hospitals to the private sectors. None of the hospitals outsourced the nursing services.

- This study showed that nutrition services had been outsourced to the private sector more than other services, five of the six hospitals, and radiology and laboratory services were outsourced by only one hospital.

- The highest propensity for outsourcing services among the hospital managers was nutrition followed by laboratory, radiology and nursing services.

- Effective national policy should be developed to engage the private sectors to improve public health by outsourcing health services.

Correspondence: Fateme Setoudehzadeh, PhD Student, Department of Health policy, Tehran University of Medical Science, Tehran, Iran. E-mail: fsetudezade@gmail.com. 
health system and, at the same time, create an environment for cooperative and competitive business sector. ${ }^{4}$ One main reason hospital managers choose to outsource support services is to reduce operating costs while increasing quality of services to the patient. ${ }^{5}$

Recently, outsourcing has become one of the healthcare sector's buzzwords. ${ }^{6}$ The main drivers for outsourcing in healthcare organization are cost minimization, risk mitigation, adapting to quick changes and value stream redefining. ${ }^{7,8}$ One universities in Iran have also started outsourcing the services, installation, nursing, food distribution, and transportation units to the private sector since 2000. ${ }^{9}$ Although outsourcing the nonclinical services has been highly successful, it has been accompanied by some risks regarding the clinical services. The study in the USA revealed a two-fold growth in the trend of outsourcing the nursing services from 1994 to $1995 .{ }^{10}$ However, the studies performed in other countries showed the lack of propensity for outsourcing the clinical services. For instance, Young ${ }^{11}$ conducted a study in Australia showed that none of the clinical services had been outsourced to the private sector except for radiology and pharmacy. In fact, the hospital managers had argued that outsourcing these services would lead to no financial saving and, at the same time, would create problems regarding patient care. ${ }^{11}$ Hsiao et al. ${ }^{12}$ carried out a study in Taiwan and revealed that less than $3 \%$ of nutrition, pharmacy, and nursing services had been outsourced to the private sector. This implies that Taiwan's hospitals are still conservative in outsourcing the clinical services. On the contrary, Tabibi et al. ${ }^{13}$ investigated the hospitals affiliated to the Ministry of Health, Iran and showed that on the average $86.29 \%$ of the nutrition services had been outsourced from 2004 to 2006 .

In general, determining the services to be outsourced is one of the major problems of the managers. ${ }^{14}$ Experience shows that a large number of organizations outsource different projects for controlling or optimizing their status before accurately investigating the conditions. ${ }^{15}$ Such wrong decisions usually impose great, inefficient expenses on the organizations and may even lead them to restore the services to the organization. ${ }^{16}$ Although attempts have been made in order to establish outsourcing committees in the universities in Iran, there are still some problems in making decisions about the services to be outsourced. ${ }^{17}$ The present study aimed to determine the present status of outsourcing hospital services (i.e. radiology, laboratory, nursing, and nutrition) to the private sectors and the propensity of the managers to outsourcing services in six hospitals affiliated to Shiraz University of Medical Sciences, Iran.

\section{Materials and Methods}

A cross-sectional study was conducted to identify the present status of outsourcing hospital services (i.e. radiology, laboratory, nursing, and nutrition) to the private sectors and the propensity of the managers to outsourcing services in six hospitals affiliated to Shiraz
University of Medical Sciences, Iran. The hospitals were selected as their services were outsourced to the private sectors. In order to evaluate the propensity for outsourcing services, the information was collected through a validated questionnaire from the managers, financial managers, contract specialists, and supervisors the hospitals.

The questionnaire was designed by the authors in order to assess the managers' level of propensity for outsourcing the services and then reviewed by the specialists of the field to improve by making necessary changes. The questionnaire was then piloted with hospital managers and further improved based on the responses. The reliability of the questionnaire was confirmed by the cronbach's alpha 0.85 . Using the data of the pilot study for assessing the reliability of the managers' questionnaire, mean and standard deviation (SD) of the score of the managers' propensity for outsourcing were measured as 36 and 8.3, respectively. Then, considering the error of $2 \%$ as well as the confidence interval of $95 \%$ and using the mean estimation formula, a sample size of 20 managers was determined for each service.

There are four managers in each selected hospital (i.e. hospital administrator, financial manager, contract specialist, and supervisor) and therefore 24 managers were included in the study from six hospitals. Each manager answered four questionnaires as four services (i.e. radiology, laboratory, nursing, and nutrition) were investigated, and a total of 96 questionnaires were distributed among managers. The study was approved by the Ethical committee of Shiraz University of Medical Sciences.

\section{Results}

The findings of the study revealed that radiology, laboratory and nutrition services were being outsourced by the hospitals to the private sectors. None of the hospitals outsourced the nursing services. Nutrition service was outsourced by five of the six hospitals, and radiology and laboratory services were outsourced by only one hospital.

The findings of the study showed that highest number $(87 \%)$ of the managers had a tendency toward outsourcing the nutrition service. In addition, $73.9 \%$, $62.2 \%$, and $43.4 \%$ of the managers had a tendency for outsourcing the laboratory, radiology and nursing services, respectively (Table 1).

\section{Discussion}

The present study aimed to determine the present status of outsourcing hospital services (i.e. radiology, laboratory, nursing, and nutrition) to the private sectors and the propensity of the managers to outsourcing services in six hospitals affiliated to Shiraz University of Medical Sciences, Iran. The findings of the study provide the evidence-based information and could be used by the hospital managers and policymakers to take appropriate decision regarding the outsourcing the 
Table 1: Propensity of the managers to outsource hospital services

\begin{tabular}{|l|c|c|c|c|c|c|c|}
\hline \multirow{2}{*}{$\begin{array}{c}\text { Type of } \\
\text { services }\end{array}$} & \multicolumn{5}{|c|}{ Respondents (\%) } & \multirow{2}{*}{$\begin{array}{c}\text { \% of managers who } \\
\text { agreed with service } \\
\text { outsourcing }\end{array}$} \\
\cline { 2 - 7 } & $\begin{array}{c}\text { Completely } \\
\text { agree }\end{array}$ & Agree & No idea & Disagree & $\begin{array}{c}\text { Completely } \\
\text { disagree }\end{array}$ & & $\begin{array}{c}\text { Total } \\
\text { Nursing }\end{array}$ \\
\hline (13\%) & $7(30.4 \%)$ & $4(17.4 \%)$ & $7(30.4 \%)$ & $2(8.7 \%)$ & 23 & $43.4 \%$ \\
\hline Radiology & $6(25 \%)$ & $10(41.7 \%)$ & $1(4.2 \%)$ & $3(12.5 \%)$ & $4(16.7 \%)$ & 24 & $62.2 \%$ \\
\hline Laboratory & $7(30.4 \%)$ & $10(43.5 \%)$ & $2(8.7 \%)$ & $4(17.4 \%)$ & 0 & 23 & $73.9 \%$ \\
\hline Nutrition & $12(52.2 \%)$ & $8(34.8 \%)$ & 0 & $3(13 \%)$ & 0 & 23 & $87 \%$ \\
\hline
\end{tabular}

services to the private sectors. The study demonstrated that nutrition service was outsourced by most of the hospitals and $87 \%$ of the managers had expressed their intention to outsource nutrition service.

The findings of the study also identified that managers have a low level of propensity for outsourcing the nursing services. This issue was also confirmed by the present status of outsourcing the nursing services in the hospitals under study. The managers' low level of propensity for outsourcing the clinical services has also been confirmed by the studies conducted Australia ${ }^{11}$ and Taiwan. ${ }^{12}$ In fact, they believed that outsourcing clinical services would result in no financial savings and, at the same time, might negatively affect the quality of the services provided to the patients. In the same line, the findings of the studies conducted by the Iranian Researchers Group ${ }^{18}$ in 2003 to investigate the overall status of outsourcing of hospital services of universities of medical sciences revealed that support services have been outsourced to a greater extent in comparison to healthcare services. This might be due to the high complexity of healthcare services as well as the availability of limited number of contractors who have the capability of providing quality services. ${ }^{18}$ Most of the studies conducted on outsourcing hospital services have highlighted the organizations' conservativeness in outsourcing the nursing services. However, in the USA a two-fold growth in the trend of outsourcing the nursing services was observed from 1994 to 1995 , which confirmed the increase in the managers' propensity for outsourcing the nursing services in the USA. ${ }^{10}$

The results of the present study also showed the managers' inclination towards outsourcing radiology and laboratory services. Of course, investigation of the status of outsourcing these two services in the Shiraz hospitals showed that in spite of the managers' high propensity for outsourcing the radiology as well as laboratory services, only a limited number of the hospitals had outsourced the two services. This might be due to the limited number of qualified contractors for providing quality services as mentioned earlier. ${ }^{18}$ The high propensity for outsourcing the nutrition services may be due to a availability of great number of contractors to provide this and nutrition service does not directly related to the patient care. The study conducted by the Iranian Researchers Group in universities of medical sciences revealed a high propensity for outsourcing the support services to the public sectors. ${ }^{18}$
This was due to the relative simplicity of support services and availability of the large number of contractors for providing such services. Tabibi et al. ${ }^{13}$ found that $86.29 \%$ of the nutrition service had been outsourced in the hospitals affiliated to the Ministry of Health, Treatment, and Medical Education. Outsourcing services to private sectors has been a trend in the health care industry also noticed in other countries. In the USA, the numbers outsourcing of health care food services increased $40-45 \%$ in comparison to $15-25 \%$ in early 1990 s. $^{19,20}$ A nationwide survey of clinical dietitians and clinical nutrition managers conducted in the USA found that $35.3 \%$ of the respondents indicated that management of both patient and cafeteria food services was outsourced. ${ }^{21}$

Contracting out of health services to the private sectors has been the subject of extensive debate and discussion among health personnel and policymakers. ${ }^{22}$ It has to be noted that contracting is not synonymous with privatization of health services. ${ }^{23}$ It provides opportunities to better utilize the private services to improve health system performance in relation to access, equity, quality and efficiency. ${ }^{15,23}$ However, the process is challenging and requires transparent procedures, effective monitoring/legal mechanisms and favorable political environment. ${ }^{15}$

\section{Conclusion}

This study showed that nutrition services had been outsourced to the private sector more than other services. In addition, hospital managers had also high propensity for outsourcing the nutrition services. In spite of the managers' high propensity for outsourcing the radiology as well as laboratory services, only a limited number of the hospitals had outsourced the two services, which may be due to non-availability of quality service and contractors in the private sectors. Hospital managers and health policy makers should pay more attention to the characteristics of services, besides considering the costs, while outsourcing the services. An effective national policy should be developed to engage the private sectors to improve public health by outsourcing health services.

\section{Acknowledgement}

The present study was financially supported by Shiraz University of Medical Science (Grant No: 89-5529). We would like to thanks all managers and personnel who cooperation in this study. 


\section{References}

1. World Health Organization. The World Health Report 2000: Health Systems Improving Performance. Geneva: WHO, 2000.

2. Drechsler D, Jütting J. Private Health Insurance for the Poor in Developing Countries? Policy Insights No. 11. Paris: OECD Development Centre, 2005.

3. Deshpande V, Schwarz1 L B, Atallah ML, Blanton M, Frikken KB. Outsourcing Manufacturing: Secure Price-Masking Mechanisms for Purchasing Component Parts, POM J 2011;20(2):165-80.

4. Editorial. Necessary scientific approach to outsourcing strategies. J Tadbir 2005;16(166):2-3.

5. Sunseri R. Outsourcing on the Outs. Hosp Health Network 1999:73(10):46-52.

6. Guimarães CM, de Carvalho JC. Outsourcing in health care sector - a state-of-the-art review. Supply Chain Forum 2011;12(1):140-8.

7. Alper, M. New trends in healthcare outsourcing. Employee Benefit Plan Review 2004;58(8):14-6.

8. Bhattacharya S, Behara, RS, Gundersen, DE. Business risk perspective on information system outsourcing. Int J Account Inform Syst 2003;4:75 -93 .

9. Sharif ZM. Measure the effectiveness of the privatization of Medical Sciences and Health Services, Isfahan province. J Homa-ey-Salamat 2005;21:15-20.

10. Vining AR, Globerman S. Contracting-out health care services: a conceptual framework. Health Policy 1999;2(16):77-96

11. Young S. Outsourcing in the Australian health sector. International J Public Sector Manag 2005;18(1):25-36.

12. Hsiao CT, Pai JY, Chiu H. The study on the outsourcing of Taiwan's hospitals. BMC Health Serv Res 2009;13(9):78
13. Tabibi S, Kakhani M, Ehsani Chimeh E. An evaluation of the outsourcing strategy in supportive services in the hospitals affiliated to the Ministry of Health and Medical Education. $J$ Health Admin 2008;10(30):59-66.

14. Moschuris SJ, Kondylis MN. Outsourcing in public hospitals: a Greek perspective. $J$ Health Organ Manag 2006; 20(1):4-14.

15. Siddiqi S, Masud TI, Sabri B. Contracting but not without caution: experience with outsourcing of health services in countries of the Eastern Mediterranean Region. B World Health Organ 2006;84(11):867-75.

16. Mehdianfar M, Salari, E. Troubleshooting complicated outsourcing: Internal Vice Magazine plan, 2009; 36. http://news.um.ac.ir/news-filessaman36.pdf (accessed June 2014)

17. Ashrafzade F. Comprehensive model for outsourcing services: J Tadbir 2004;15(147):415.

18. Iranian expert group company. Study methods of reduce support services Policies of Medical Universities: 2003. http://nikanlink.com/ product/10876/333 (accessed June 2014)

19. De Micco FJ, Williams JA. A current perspective on institutional/contract foodservice management: The one lost and found "I" in HR\&IM. Hospitality Tourism Educ 1996;8:15-8.

20. McCool AC, Smith FA, Tucker DL. Dimensions of Noncommercial Food service Management. New York: Van Nostrand Reinhold, 1994.

21. Kwon J, Yoon BJ. Prevalence of outsourcing and perception of clinical nutrition managers on performance of health care: $J$ Am Diet Assoc 2003; 103(8):1039-42.

22. World Health Organization. The role of contractual arrangements in improving health sector performance: experience from countries of the Eastern Mediterranean Region. Egypt: WHO, 2006.

23. Loevinsohn B, Harding A. Buying results? Contracting for health service delivery in developing countries. Lancet 2005;366:676-81. 